\title{
INFLUENCE OF SOLAR RETROGRADE MOTION ON TERRESTRIAL PROCESSES
}

\author{
N.S.Sidorenkov ${ }^{1}$, Ian Wilson ${ }^{2}$ \\ ${ }^{1}$ Hydrometcenter of the Russia, Moscow, sidorenkov@mecom.ru \\ 2 The Liverpool Plains Daytime Astronomy Centre, Curlewis, NSW, Australia, \\ irgeo8@bigpond.com
}

\begin{abstract}
The influence of solar retrograde motion on secular minima of solar activity, volcanic eruptions, climate changes, and other terrestrial processes is investigated. Most collected data suggest that secular minima of solar activity, powerful volcanic eruptions, significant climate changes, and catastrophic earthquakes occur around events of solar retrograde motion.
\end{abstract}

Keywords: barycentric motion of the sun; secular minima of solar activity, volcanic eruptions, climate changes; the historical process of humankind.

\section{Barycentric motion of the sun}

The amplitude of the 24th 11-year cycle of solar activity was found to be the smallest over the last 200 years. Even smaller amplitudes of 11-year sunspot cycles were observed only during the Dalton Minimum. What is the cause of this decay of the amplitude of the 11-year sunspot cycle? The most plausible explanation of this phenomenon can be provided by the Jose cycle (Jose, 1965), which he obtained by calculating the trajectory of solar motion around the center of mass of the solar system. Let us look at his work more closely.

The planets rotate around the Sun. The Sun moves around the center of inertia of the solar system, which is hereafter called the barycenter. The trajectory of the Sun (cardioid) has the form of a fourth-order quasi-periodic curve (conchoid of a circle). It usually moves counterclockwise around the barycenter. However, at very rare times, the center of the Sun moves so that the barycenter turns out to be outside the cardioid. In these cases, the Sun passes the barycenter clockwise, so Jose called these events solar retrograde motion. The last event was observed about the year 1990 (Fig. 1). Jose (1965) showed that such events happen every 178.7 years. Earlier events of solar retrograde motion occurred about the years 1811, 1632, 1454, 1275, $1096,918,739,560,382,203,24,-154$, and -333 .

Jose (1965) found the relation between the 179-year period of solar retrograde motion and the similar cyclicity of solar activity. At present, solar activity records are available over the last thousand years. Amplitude beats between the 11-year solar activity cycle and its secular maxima and min- ima have been established. The minima are given the names of scientists who made the greatest contribution to their study (see the first column in Table 1). The second and third columns list approximate times of beginning and end of solar spot minima, and the fourth column gives the times of solar retrograde motion. The differences between the beginning (middle) of a solar activity minimum and solar retrograde motion is given in the sixth column. A comparison of them shows that, in all five cases, the secular minima of solar activity approximately agree with the times of solar retrograde motion (with a delay of approximately 18 years). Unfortunately, this sample is too small for the hypothesized relation between the secular solar activity minima and the events of solar retrograde motion to be justified statistically, but there is no ground to reject it, especially as, on small scales (as compared with the solar system), the influence exerted by features of the Earth's monthly rotation around the center of inertia of the Earth-Moon system can easily be observed in weather and climate variations (Sidorenkov, 2016).

Taking into account what was said above, it can be concluded that the amplitude decay for the 24th 11-year cycle suggests the onset of a new secular minimum of solar activity, which was predicted, together with its consequences, by Landscheidt (2003).

\section{Volcanic explosions}

It is well known that secular minima of solar activity are associated with climate cooling on the Earth. Climatologists explain them by stratospheric sulfur compound pollution caused by explosive volcanic eruptions.

In volcanic explosions, eruption products are injected into the stratosphere, spread over the globe, and gradually descend, specifically, on the Antarctic and Greenland ice sheets. As snow falls, they get buried progressively deeper and the snow turns into ice. An analysis of ice cores produced by drilling provides information on volcanic eruptions over the globe in the far past.

Data on volcanic activity and the stratospheric annual content of sulfate aerosol (sulfate ion $\mathrm{SO}^{2-}{ }_{4}$ ) were obtained by Traufetter et al. (2004) by analyzing ice cores drilled in Queen Maud Land in western Antarctica. These data can 
be found at http://www.ncdc.noaa.gov/paleo/icecore/ antarctica/domec/domec. New data on volcanic aerosol concentrations in the stratosphere over the last 2000 years were obtained in (Clausen et al., 2012; Sigl et al., 2013). Below, we use data from (Sigl et al., 2013).

The stratospheric aerosol consists, to a large degree, of tiny droplets of sulfuric acid. It reflects solar radiation in the lower stratosphere and the upper troposphere, thereby reducing the surface air temperature (Borzenkova and Bruk, 1989). Figure 2 illustrates temperature variations in the Northern Hemisphere extratropical zone (upper curves) and variations in the stratospheric $\mathrm{SO}^{2-}$ concentration (lower histogram).

In the period between the years 700 and 1200, the volcanic activity was weak, so the stratospheric aerosol con- centrations were low. As a result, the Medieval Warm Anomaly (MWA) was observed.

In the middle of the 13th century (near the solar retrograde motion event in 1275) there was a powerful eruption of the Samalas volcano (Indonesia) (1258-1261) along with a prolonged series of less intense eruptions. As a result, a thick aerosol layer formed in the stratosphere, which led to strong absorption of solar radiation and, as a consequence, to a decrease in surface air temperature. In the 14th century, volcanic eruptions were few, so the transparency of the atmosphere increased and the surface air temperature rose. Near solar retrograde motion in 1454, a powerful eruption of the Kuwae volcano (1458$1461)$ again led to strong cooling. The retrograde motion events in 1633 and 1811 were also accompanied by strong volcanic eruptions facilitating climate cooling.

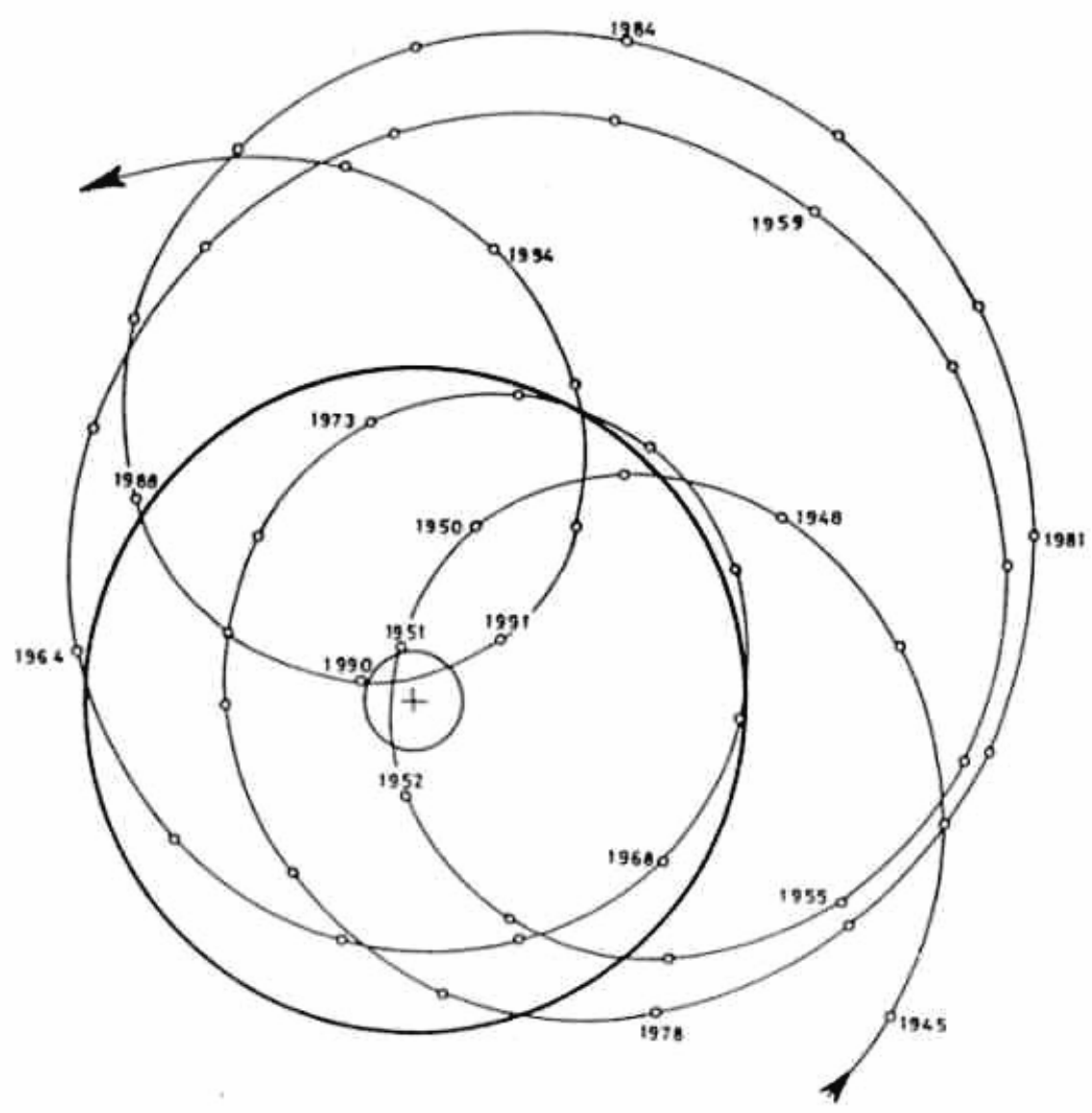

Figure 1: Path of the Sun in the barycentric ecliptic coordinate system for the period from 1945 to 1995. The solar system barycenter is denoted by + (Landscheidt, 2003).

Table 1. Secular minima of solar activity and times of solar retrograde motion

\begin{tabular}{|c|c|c|c|c|}
\hline Minimum name & Start & End & $\begin{array}{c}\text { Retrograde } \\
\text { motion }\end{array}$ & Difference \\
\hline Oort & 1040 & 1080 & 1096 & -36 \\
\hline Wolf & 1280 & 1350 & 1275 & 40 \\
\hline Spörer & 1450 & 1550 & 1454 & 46 \\
\hline Maunder & 1645 & 1715 & 1632 & 48 \\
\hline Dalton & 1790 & 1820 & 1811 & -6 \\
\hline Landscheidt & 2009 & 2040 & 1990 & - \\
\hline & \multicolumn{3}{|c|}{ Average } \\
\hline
\end{tabular}




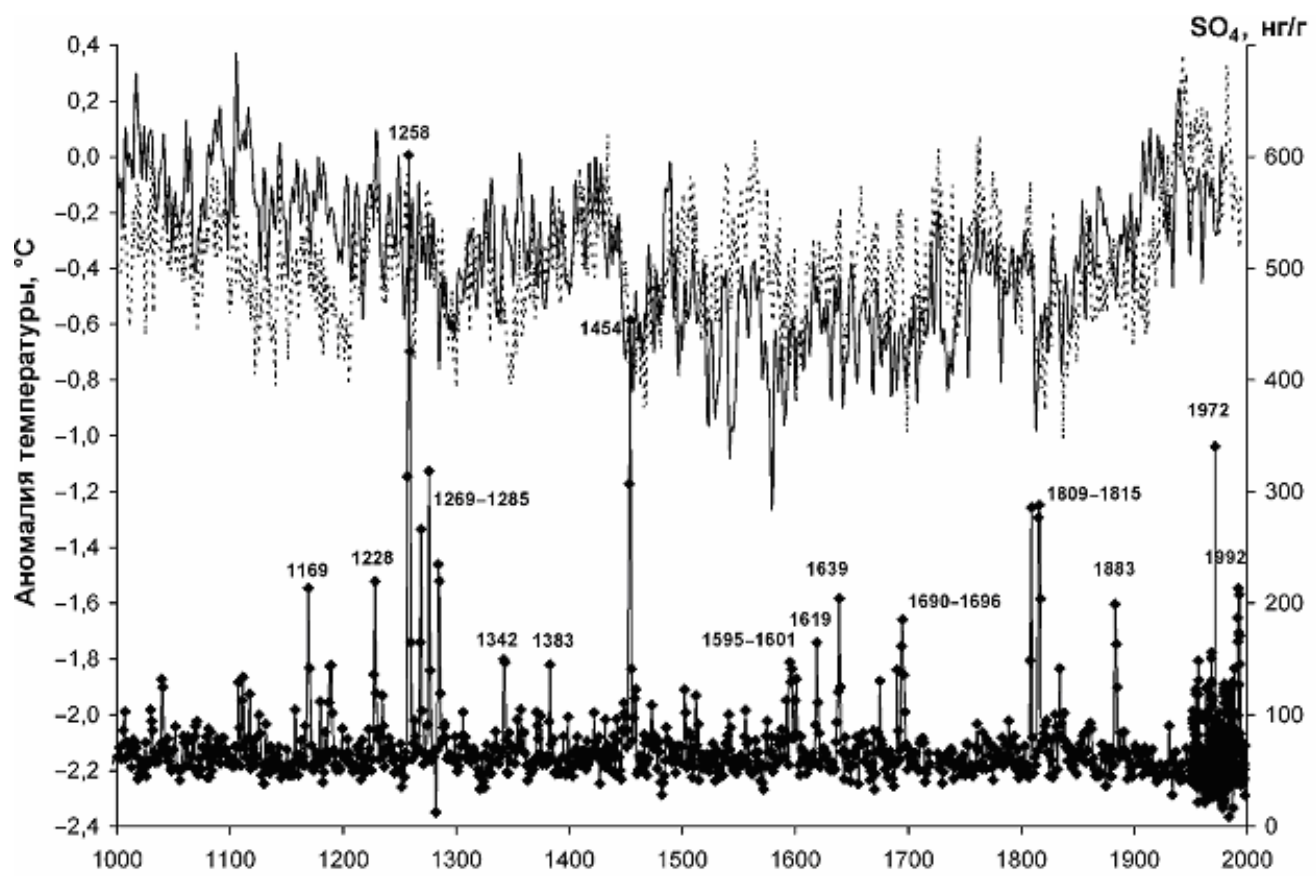

Figure 2: Annual air temperature anomalies in the Northern Hemisphere (data from (Moberg et al., 2005) are shown by solid lines, and the data from (D'arrigo et al., 2006), by dotted lines) and the stratospheric $\mathbf{s o}^{2-}{ }_{4}$ concentrations inferred from antarctic ice core data (Traufetter et al., 2004) over the last 1000 years [http://www.ncdc.noaa.gov/paleo/icecore/ antarctica/domec/domec]. The plot is taken from (Borzenkova et al., 2011)

\section{Centuries cold period}

The period from 1600 to 1840 was the longest cold period in the Northern Hemisphere over the last 1000 years. Climate warming did not begin until 1840, and it still persists with small oscillations.

Borzenkova et al. (2011a) identified long periods (1260-1350, 1420-1570, 1620-1710, and 1780-1830) when volcanic eruptions had the largest effect on the global air temperature. All of them coincide with the corresponding events of solar retrograde motion in $1275,1454,1632,1811$ ! The same periods of reduced transparency in the upper atmosphere are associated with the cases of most significant cooling in the Northern Hemisphere, which are part of the longest (over the last 1000 years) cooling epoch known as the Little Ice Age. This long cold period was caused by persistently high stratospheric aerosol concentrations maintained by intense volcanic activity (powerful eruptions in the years 1452/1453, 1458/1459, 1600/1601, 1809/1815, 1835 , etc.).

Until the middle of the 19th century, the air temperature variations in the Northern Hemisphere were determined by transparency oscillations in the upper troposphere and the lower stratosphere caused by the presence of aerosol of mainly volcanic origin (Borzenkova et al., 2011). Inspection of Fig. 2 shows that the highest peaks of stratospheric volcanic aerosol can be associated with events of solar retrograde motion. The spectral analysis of series of sulfate aerosol concentration reveals a period of about 180 years (Borzenkova et al., 2011) coinciding with a Jose cycle (Jose, 1965).

\section{The last 1990 event}

Windelius and Tucker (1988), noting the increased seismic and volcanic activity during the previous events of solar retrograde motion in 1811 and 1632, warned of the danger of its recurrence in connection with the approaching event of solar retrograde motion in 1990.

Indeed, the last 1990 event of solar retrograde motion can be associated with the eruptions of El Chichón (Mexico) in 1982 and Pinatubo (Philippines) in 1991. In the latter case, as much as $25.4 \pm 2.8 \mathrm{~kg} / \mathrm{km}^{2}$ of sulfate ion $\mathrm{SO}^{2-}$ was injected into the stratosphere. The effects of the Pinatubo eruption were felt worldwide. It ejected more aerosols into the stratosphere than any eruption since Krakatau in 1883. Over the following months, a global layer of sulfuric acid haze was observed in the atmosphere. Global temperatures dropped by $0.5{ }^{\circ} \mathrm{C}$, and ozone layer depletion increased substantially; specifically, an especially large ozone hole was formed over Antarctica.

Catastrophic earthquakes were observed only on December 24, 2004, in the Indian Ocean (magnitude of about 9.3; the loss of life was estimated to be between 225 and 300 thousand people). An earthquake of magnitude of 9.0 to 9.1 occurred on March 11, 2011, in Japan. It was followed by a strong tsunami and led to the Fukushima nuclear disaster.

In 1990, there began a weak El Nino event, which continued extremely long until June, 1995. The strongest El Nino events in historic times occurred in 1983, 1987, and 1998.

Landscheidt (2003) believes that a new little ice age is to be expected instead of global warming. 


\section{Historical processes}

A hundred years ago, Chizhevsky (1924) hypothesized that solar activity affects historical processes. The collapse of the Soviet Union and Yugoslavia occurred about the event of solar retrograde motion in 1990, the Napoleonic wars broke out about the event of 1811, the Time of Troubles in Russia and the splitting of the Russian Orthodox Church were about the event of 1632, and the Mongol invasion of Russia happened about the event of 1275 . This evidence suggests that historical processes in Russia are possibly connected with events of solar retrograde motion. There are similar comparisons of historical events in China with secular minima of solar activity, which suggest nearly the same connection.

\section{Conclusion}

Unfortunately, the events of solar retrograde motion covered by available series of empirical data are insufficient for the hypothesized dependence of terrestrial events on solar retrograde motion to be justified statistically. However, most collected data suggest that secular minima of solar spots, powerful volcanic explosions, catastrophic earthquakes, substantial climate changes, and significant historical social events happen most frequently around events of solar retrograde motion.

The variability of terrestrial processes and events are usually tried to be connected with solar activity. However, solar activity cannot affect the motion of the Sun around the solar system barycenter. Therefore, from a physical point of view, it is more natural to suppose that processes occurring on the Sun, the Earth, and solar system planets are affected by the barycentric motion of the Sun governed by gravitation. This conclusion is also supported by the author's results obtained in the study of effects produced by the Earth's monthly motion around the Earth-Moon system barycenter (Sidorenkov, 2016).

Acknowledgments. I am grateful to I.I. Borzenkova for her assistance with this work.

This study was supported by the Russian Foundation for Basic Research, project 15-05-075590.

\section{References}

Borzenkova I.I. and Bruk S.A.: 1989, Trudy. Gos. gidrol. inst., 347, 40.

Borzenkova I.I., Zhil'tsova E.L., Lobanov V.A.: 2011, In: Problems in ecological modeling and ecosystem monitoring (Planeta, Moscow), 131.

Chizhevsky A.L.: 1924, Physical factors of historical processes (Kaluga, 1924) [In Russian].

Clausen H.B., Vinther B.M., Mayewski P.A.: 2012, Climate of the past, 8, 19291940.

D'arrigo R., Wilson R., Jacoby G.: 2006, J. Geophys. Res., 111, No. D03103. DOI: 10.29/2005JD006352.

Jose P.B.: 1965, A. J., 70, No. 3, 193.

Landscheidt T.: 2003, Energy and Environment, 14, 4.

M'berg A., Sonechkin D. M., Holmgren K. et al.: 2005, Nature, 433, No. 7026, 613.

Sigl Michael, McConnell Joseph R., Layman Lawrence, et al.: 2013, J. Geophys. Res., 118, 1151, doi:10.1029/2012JD018603

Traufetter F., Oerter H., Fischer H. et al.: 2004, J. Glaciology, 50, No. 168, 137.

Sidorenkov N.S.: 2016, Izvestiya, Atmospheric and Oceanic Physics, 52, No. 7, 667, Pleiades Publishing, Ltd., DOI: 10.1134/S0001433816070094.

Windelius G., Tucker P.: 1988, Solar motion, Seismicity, Climate. Drottning Holm, Sweden, 41 p. 